\title{
MINERALOGIA DAS FRAÇÕES AREIA, SILTE E ARGILA DE SEDIMENTOS DO GRUPO BARREIRAS NO MUNICÍPIO DE ARACRUZ, ESTADO DO ESPÍRITO SANTO(1)
}

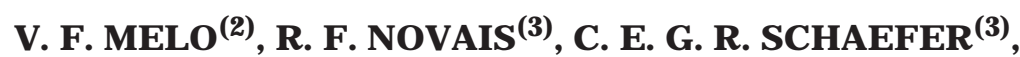 \\ M. P. F. FONTE $S^{(3)} \&$ B. SINGH ${ }^{(4)}$
}

\begin{abstract}
RESUMO
Dada a extensa área ocupada pelos sedimentos do Grupo Barreiras, é importante conhecer detal hadamente a mineralogia de suas frações. Com este propósito, coletaram-se 11 amostras, até $14 \mathrm{~m}$ de profundidade, em um pacote de sedi mentos do Grupo Barreiras no município de Aracruz, estado do Espírito Santo, exposto pela construção de um canal adutor de água. As frações areia, silte e argila foram estudadas por difração de raios-X, análise termodiferencial, análise termogravimétrica diferencial e microscopia eletrônica. Os teores totais de Fe das frações argila e silte e Ti e Zr da fração silte foram determinados por espectrometria por emissão por plasma, após digestão da amostra com ácido fluorídrico concentrado. Para caracterizar e quantificar os minerais, amostras das frações argila e silte foram submetidas a extrações seqüenciais e seletivas dos minerais. A fração areia apresentou mineralogia uniforme, composta quase que exclusivamente por quartzo, com pequena presença de mica, anatásio e agregados de caulinita e ferro. Nas profundidades de 2,1; 4,2 e 7,7 m, verificouse a ocorrência de concreções ferruginosas de coloração vermelho-escura. $\mathrm{Na}$ fração silte, também com predomínio de quartzo, verificou-se a presença de caulinita, na forma de agregados estáveis e hematita. A caulinita é o principal mineral da fração argila, atingindo $953 \mathrm{~g} \mathrm{~kg}^{-1}$ a $14 \mathrm{~m}$ de profundidade. Os baixos teores de Fe dos sedimentos e as condições úmidas dos Tabuleiros Costeiros favoreceram a concentração de caulinita e a remoção de minerais, principal mente óxidos de Fe. Os teores de goethita, principal óxido de ferro dos sedimentos,
\end{abstract}

(1) Parte da Tese de Doutorado do primeiro autor. Recebido para publicação em outubro de 2000 e aprovado em abril de 2001.

(2) Professor do Departamento de Solos, Universidade Federal do Paraná - UFPR. Rua dos Funcionários, 1540, J uvevê, CEP 80035050 Curitiba (PR).

(3) Professor do Departamento de Solos, Universidade Federal de Viçosa - UFV. CEP 36571-000 Viçosa (MG).

(4) Department of Agricultural Chemistry and Soil Science. The University of Sydney. N.S.W. 2006 Austrália. 


\begin{abstract}
diminuíram consistentemente em profundidade. Em decorrência do elevado grau de alteração dos sedimentos, a quantidade de material de baixa cristalinidade na fração argila foi pequena, variando de 3,2 a $24,0 \mathrm{~g} \mathrm{~kg}^{-1}$, para extração com oxalato de amônio, e de 0,6 a $3,5 \mathrm{~g} \mathrm{~kg}^{-1}$, para extração com $\mathrm{NaOH}$ $0,5 \mathrm{~mol} \mathrm{~L}^{-1}$ fervente. Pelo mesmo motivo, os teores de mica nas frações argila e silte foram inferiores a $5,0 \mathrm{~g} \mathrm{~kg}^{-1}$. Como observado para a caulinita, os teores de mica na fração argila aumentaram em profundidade.
\end{abstract}

Termos de indexação: extração seqüencial, caulinita, óxidos de ferro, minerais com baixa cristalinidade.

\title{
SUMMARY: MINERALOGY OF THE SAND, SILT AND CLAY FRACTIONS OF BARREIRAS GROUP SEDIMENTS IN ARACRUZ, ESPÍRITO SANTO STATE, BRAZIL
}

\begin{abstract}
To investigatethemineral ogical variati ons with depth, 11 samples werecollected down to $14 \mathrm{~m}$, in an exposed sediment packet of the Barreiras Group in Aracruz, Espírito Santo, Brazil. The sand, silt and clay fractions were studied by X-ray diffraction, differential thermal analysis, thermogravimetry and electron microscopy. The total contents of $\mathrm{Fe}$ in the clay and silt fractions and $\mathrm{Ti}$ and $\mathrm{Zr}$ in the silt fraction were determined by ICP after fluoridric acid extraction. Clay and silt fractions weresubmitted to selectiveand sequential mineral extractions, to characterize and quantify their constituents. The sand fraction showed a uniform mineralogical composition, al most sol el y quartz, with small amounts of mica, anatase, kaoliniteand iron aggregates. In the 2.1; 4.2 and 7.7 m depths, theoccurrence of iron mottles with dark-red colour was observed. Silt fraction, as well, is constituted mainly by quartz, with stabl ekaol initeaggregates and hematite. Theclay fraction showed a high proportion of kaol inite, reaching $950 \mathrm{~g} \mathrm{~kg}^{-1}$ at $14 \mathrm{~m}$ depth. Thel ow contents of Fein the sediments and the humid conditions of the Coastal Tablelands favored kaolinite concentration and removal of minerals, mainly Fe oxides. Contents of Goethite (main Fe oxi dein thesediment) decreased with depth. Theamount of low cristalinity material in the clay fraction is small, varying from 3.2 to $24.0 \mathrm{~g} \mathrm{~kg}^{-1}$ for ammonium oxalate extraction and from 0.6 to $3.5 \mathrm{~g} \mathrm{~kg}^{-1}$ for extraction with $0.5 \mathrm{~mol} \mathrm{~L}^{-1} \mathrm{NaOH}$, due to the high degree of devel opment of the sediments. For the same reason, the mica contents in the clay and silt fractions were lower than $5.0 \mathrm{~g} \mathrm{~kg}^{-1}$. As observed for kaol inite, the mica content in theclay fraction increased with depth.
\end{abstract}

Index terms: Sequential extraction, kaol inite, iron oxides, low cristalinity minerals.

\section{INTRODUÇÃO}

Os depósitos de sedimentos do Grupo Barreiras ocupam a faixa litorânea e parte da faixa sublitorânea de quase toda a Costa Oriental e Setentrional do Brasil, desde o Rio de J aneiro, estendendo-se para norte, até à Bacia Amazônica (Mabesoone, 1966; Bigarella, 1975). Esses sedimentos são de origem fluvial e sua fonte é atribuída ao desmonte de grandes áreas continentais soerguidas. A sedimentação ocorreu no Terciário, prol ongando-se até o Quaternário (Petri \& Fúlfaro, 1983). Sãosedimentos ti picamentecom baixos teores de $\mathrm{Fe}$, desenvolvidos, cauliníticos, com esqueleto quartzoso mal selecionado, o que favorece, sobremaneira, o adensamento dos solos deles originados (Zangrande, 1985; Arcanjo, 1990).
No estado do Espírito Santo, os sedimentos do Terciário formam os tabulei ros costei ros, distribuídos ao longo do litoral, em discordância sobre as rochas do Pré-Cambriano Indiviso ou sobre intrusivas ácidas. Esses sedimentos são de caráter argiloso, argilo-arenoso ou arenoso, sendo os últimos, em geral, de idade mais recente (Quaternário). Os sedimentos Quaternários distribuem-se em aluviões atuais ou antigos, ao longo dos val es ecal has fluviais e apresentam-se, em geral, não consolidados. É comum a presença de estratos laterizados vermel hoescuros a lilás, com até 4,0 m de espessura, em vários níveis de sedimentação (Amador, 1982).

A fração grosseira dos solos desenvolvidos de sedimentos do Grupo Barreiras é constituída basicamente de quartzo, com algumas concreções ferruginosas e traços de turmalina, rutilo, zircão, 
ilmenita, biotita e muscovita (J acomine, 1974; Achá Panoso, 1976; EMBRAPA, 1978; EMBRAPA, 1996; Duarte et al., 2000). Na fração argila, predomina a caulinita, sendo a presença deóxidos de Felimitada pel os baixos teores de Fe do material de origem. Melo (1998) e Duarte et al. (2000) também observaram a presença de gibbsita (em torno de $50 \mathrm{~g} \mathrm{~kg}^{-1}$ ) e pequenas quantidades de quartzo, anatásio e mica. São, portanto, sedimentos mineralogicamente bastante estáveis e resistentes ao intemperismo (E mbrapa, 1978; Mattos, 1979).

O objetivo deste trabalho foi caracterizar e quantificar os minerais presentes nas frações areia, silte e argila no solo e no sedimento do Grupo Barreiras, no município de Aracruz (ES).

\section{MATERIAL E MÉTODOS}

\section{Amostragem}

As amostras foram coletadas de acordo com a profundidade em sedimentos do Grupo Barreiras, às margens de um canal adutor deáguas (Figura 1 ), no município de Aracruz a $30 \mathrm{~km}$ da costa do estado do Espírito Santo. O relevo da região compreende tabul eiros de topos aplainados, com 40 m dealtitude, entalhados por vales estreitos e de fundo chato (Duarte et al., 2000).

A amostragem foi feita em 11 pontos, nas seguintes profundidades (val ores após a correção da declividade, $45^{\circ}$, do talude do canal): 0,$7 ; 1,4 ; 2,1$; 2,$8 ; 3,5 ; 4,2 ; 4,9 ; 5,6 ; 7,7 ; 10,5$ e 14,0 m. O solo do local de amostragem foi classificado como Argissolo Amarelo (EMBRAPA, 1999), apresentando a seguinte distribuição e profundidade dos horizontes: A $(0-16 \mathrm{~cm}), A B(16-25 \mathrm{~cm}), \mathrm{Bt}(25-125 \mathrm{~cm}), \mathrm{BC}(125-$ $167 \mathrm{~cm})$ e $C\left(1,67-14,0 \mathrm{~m}^{+}\right)$. As duas primeiras amostras, 0,7 e 1,4 m, foram tomadas nos horizontes Bt eBC, respectivamente, eas demais no horizonte $C$, encontrando-se o ponto mais profundo cerca de $5 \mathrm{~m}$ acima do leito d'água. Durante a amostragem do horizonte $\mathrm{C}$, procurou-se separar as camadas de sedi mentos com características distintas, tais como: cor, presença de concreções de Fe etextura. O recente corte do talude do canal, na ocasião da amostragem, limita a ação dos fatores externos nos minerais. No momento da amostragem, cerca de $50 \mathrm{~cm}$ da parte superficial, em cada ponto, foi descartada.

\section{Remoção de matéria orgânica, separação das frações para análises químicas e mineralógicas e análise textural}

As amostras foram tratadas com hipoclorito de $\mathrm{Na}$ para remoção de matéria orgânica e com $\mathrm{NaOH}$ $0,2 \mathrm{~mol} \mathrm{~L}^{-1}$ para dispersão das frações (J ackson, 1979). A partir da profundidade de $4,9 \mathrm{~m}$, tanto na análise textural (EMBRAPA, 1979), como na separação das frações para análises químicas e

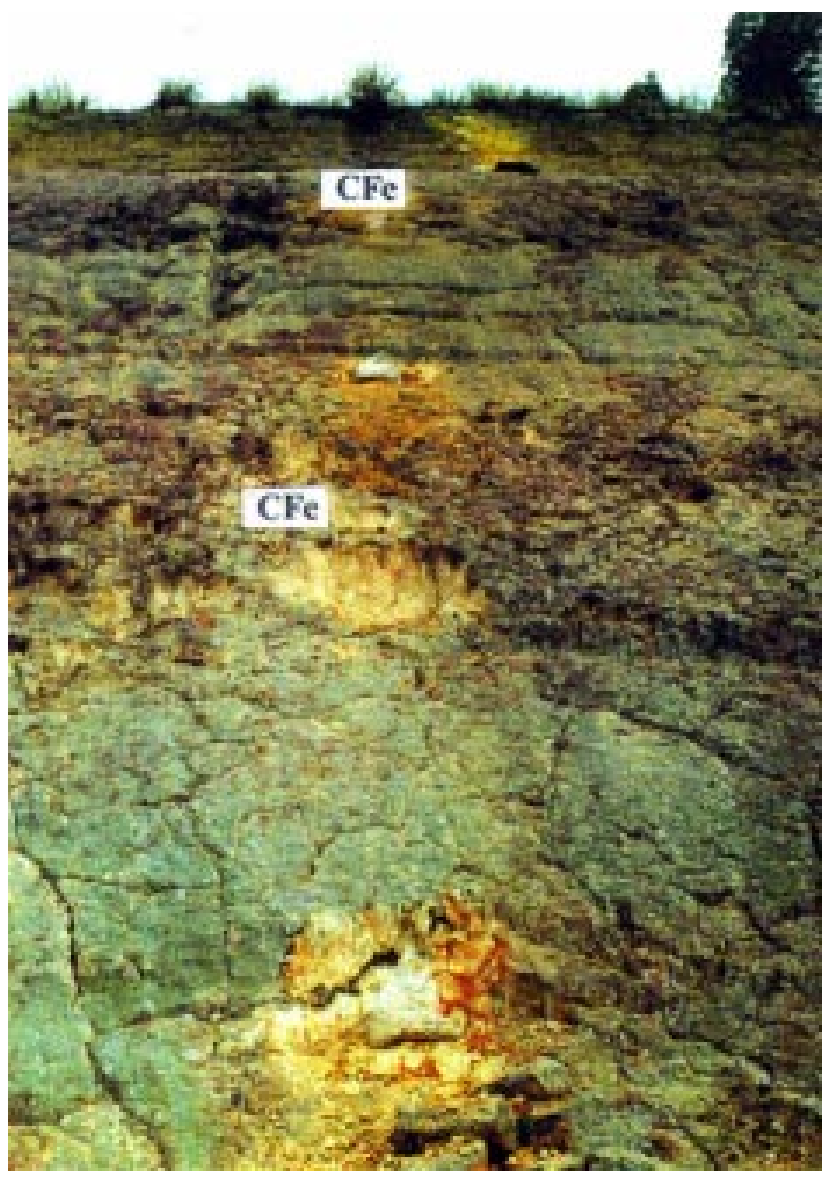

Figura 1. Amostragem em profundidade dos sedimentos do Grupo Barreiras no município de Aracruz (ES), evidenciando a formação de duas camadas enriquecidas com concreções de Fe (CFe).

mineralógicas, foi adicionada solução de hexametafosfato de sódio ( $5 \%$ p/v), para viabilizar a dispersão. A fração areia foi retida em peneira de 0,05 mm eas frações argila esilteforam separadas por sedimentação com base na lei de Stokes (Gee \& Bauder, 1986). Para garantir a separação das frações, o silte foi submetido à dispersão ultra-sônica por $10 \mathrm{~min}$. O material resultante foi recolocado em recipiente próprio para limpeza do silte por mais al guns dias, por meio de remoções periódicas da suspensão de argila sobrenadante, mantendo-se o pH em 10, pela utilização de $\mathrm{Na}_{2} \mathrm{CO}_{3}$ (1 g/10 L de água dei onizada).

\section{Análises mineralógicas e químicas}

Difração de raios-X (DRX) - Os minerais das frações argila, silte e areia (moída em almofariz) foram identificados por DRX por meio de um goniômetro vertical Philips PW 1050 controlado por computador com monocromador de grafite, radiação CuK $\alpha$ e operado a $20 \mathrm{~mA}$ e $40 \mathrm{kV}$. Os difratogramas foram obtidos numa escala de 4 a $65^{\circ} 2 \theta$ evel ocidade angular do goniômetro de $1^{\circ} 2 \theta \mathrm{min}^{-1}$. 
Análises térmicas - As frações argila e silte foram analisadas num derivatógrafo Stanton Redcroft STA-780, com saídas simultâneas dos diagramas das análises: termodiferencial (ATD) e termogravimétrica diferencial (ATGD), pelo aquecimento de $20 \mathrm{mg}$ de amostra a partir da temperatura ambiente até $1.000^{\circ} \mathrm{C}$, a uma taxa de aquecimento de $10^{\circ} \mathrm{C} \mathrm{min-1}$ sob atmosfera de $\mathrm{N}_{2}$. A interpretação qualitativa foi feita pelas características dos pi cos endotérmicos eexotérmicos dos minerais (ATD), e a análise quantitativa da caulinita (Ct) pela redução de massa da amostra (ATGD), em decorrência da desidroxilação do mineral (J ackson, 1979; Tan et al., 1986).

Teores totais de elementos - Para determinar os teores totais de elementos nas frações silte (Fe, Ti e $\mathrm{Zr}$ ) e argila (Fe), utilizou-se o método da digestão com HF concentrado apresentado por Lim \& J ackson (1986), com algumas modificações. Pelo fato de as amostras apresentarem baixos teores de matéria orgânica (apenas horizontes B e C), optou-se pela utilização apenas de $\mathrm{HNO}_{3}$, dispensando-se o emprego de $\mathrm{HClO}_{4}$. Foi colocado cerca de $0,1 \mathrm{~g}$ de amostra (pesado em bal ança de precisão com quatro dígitos) num béquer de teflon com capacidade de $50 \mathrm{~mL}$. A amostra foi umedecida com cinco gotas de $\mathrm{H}_{2} \mathrm{SO}_{4} \mathrm{e}$, em seguida, acrescentaram-se $5 \mathrm{~mL}$ de $\mathrm{HF}$ e $1 \mathrm{~mL}$ de $\mathrm{HNO}_{3}$. Os béqueres foram distribuídos em banho de areia a $230^{\circ} \mathrm{C}$, onde permaneceram por, aproximadamente, $15 \mathrm{~min}$. Uma nova porção de $5 \mathrm{~mL}$ de HF foi adicionada, e os béqueres, parcialmente tampados (cerca de 9/10), foram deixados no banho de areia por mais 30 a $40 \mathrm{~min}$, até compl eta evaporação (formação de resíduo seco).

Para garantir a dissolução dos minerais mais resistentes, adicionaram-se mais $5 \mathrm{~mL}$ de $\mathrm{HF}$, permitindo a formação de novo resíduo seco nos béqueres parcialmentetampados. Aoresíduo, foram adicionados $2 \mathrm{~mL}$ de água e quatro gotas de $\mathrm{HNO}_{3}$, deixando-se evaporar em ambienteaberto. Nofinal, para dissolução do resíduo, $5 \mathrm{~mL}$ de $\mathrm{HCl} 6 \mathrm{~mol} \mathrm{~L}^{-1} \mathrm{e}$ $5 \mathrm{~mL}$ de água foram adicionados, deixando os béqueres em banho de areia até início de fervura. Os teores de $\mathrm{Fe}, \mathrm{Ti}$ e $\mathrm{Zr}$ no extrato foram determinados em espectrômetro de emissão por plasma Perkins Elmer Optima 3000. A concentração total dos elementos foi utilizada para estimar os teores de anatásio $\left(\mathrm{TiO}_{2}\right)$, nas frações argila e silte, e de hematita $\left(\mathrm{Fe}_{2} \mathrm{O}_{3}\right)$ e zircão $\left(\mathrm{ZrSiO}_{4}\right)$, na fração silte.

Extração seqüencial e seletiva dos minerais Para quantificar os minerais presentes na fração argila, utilizaram-se extrações seqüenciais e seletivas dos minerais, na seguinte ordem (Melo et al., 2002): Argila saturada com $\mathrm{Na}$ (12 g) $\rightarrow$ Oxalato deAmônio (OA) 0,2 $\mathrm{mol} \mathrm{L}^{-1} \mathrm{pH}$ 3,0 (McKeague, 1978) $\rightarrow$ Ditionito-Citrato-Bicarbonato de $\mathrm{Na}$ (DCB)

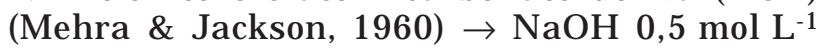

fervente (J ackson et al., 1986, com modificações) $\rightarrow$ $\mathrm{NaOH} 5 \mathrm{~mol} \mathrm{~L}^{-1}$ fervente (Norrish \& Taylor, 1961) $\rightarrow \mathrm{NaHSO}_{4}$ (cristais) (J ackson et al., 1986, com modificações) $\rightarrow$ digestão total com HF concentrado (Lim \& J ackson, 1986, com modi ficações). As análises seqüenciais na fração silte constituíram-se deapenas três etapas: Silte saturado com Na $(0,4 \mathrm{~g}) \rightarrow$ aquecimento da amostra a $550^{\circ} \mathrm{C}$ por quatro horas e extração com $\mathrm{NaOH}$ 0,5 mol L-1 fervente ( $\mathrm{J}$ ackson et al., 1986) $\rightarrow \mathrm{NaHSO}_{4}$ (cristais) (J ackson et al., 1986, com modificações) $\rightarrow$ digestão total com HF concentrado (Lim\& \& ackson, 1986, com modificações). Após cada extração, os teores de Al, $\mathrm{Fe}, \mathrm{Si}, \mathrm{K}$ e Mg foram determinados, como descrito anteriormente, com exceção de alguns tratamentos que avaliaram outros el ementos, a saber: $\mathrm{Mn}$ - OA; $\mathrm{Mn}$ eTi - DCB eNaHSO $4 ; \mathrm{Ti} \mathrm{eZr} \mathrm{-} \mathrm{digestãototal} \mathrm{com} \mathrm{HF} \mathrm{concentrado.}$ Outros procedimentos comuns às extrações seqüenciais foram: (a) o peso das amostras foram tomados em balança de precisão com quatro dígitos; (b) antes das pesagens para obtenção do peso inicial (antes da extração) e do peso final (após a extração), as amostras foram secas em estufa a $105^{\circ} \mathrm{C}$ por $12 \mathrm{~h}$; (c) para remover o excesso de sais, após cada extração, a amostra foi lavada com solução de $\left(\mathrm{NH}_{4}\right)_{2} \mathrm{CO}_{3}$ $0,5 \mathrm{~mol} \mathrm{~L}^{-1}$ eágua deionizada; (d) duranteas extrações elavagens da amostra, a suspensão foi centrifugada a $4.000 \mathrm{rpm}$ por $10 \mathrm{~min}$; (e) para o acompanhamento das variações mineralógicas, amostras foram submetidas a ATGD e DRX (lâminas orientadas e não-orientadas), após cada extração seqüencial.

A extração de alumínio e óxidos de Fe de baixa cristalinidade foi realizada em amostras de argila natural (apenas saturadas com $\mathrm{Na}$ ), utilizando apenas uma extração com OA 0,2 $\mathrm{mol} \mathrm{L}^{-1}, \mathrm{pH} 3,0$ (McK eague, 1978). As amostras resultantes do tratamento com OA foram tratadas com DCB, utilizando quatro extrações sucessivas para remoção dos óxidos de Fe de melhor cristalinidade (M ehra \& J ackson, 1960). A al umina, sílica ealuminossilicatos de baixa cristalinidade da fração argila foram extraídos por meio de solução de $\mathrm{NaOH}$ 0,5 mol L-1 fervente. Foram feitas algumas modificações no método proposto por J ackson et al. (1986). Dada a baixa cristalinidade da Ct sob condições de clima tropical úmido (Hughes \& Brown, 1979; Singh e Gilkes, 1992; Melo et al., 2001b), a relação amostra/ solução de 0,1 g:100 mL foi aumentada para 0,4 g:100 mL para reduzir a extração de Ct. Optouse pelo uso de béquer de teflon colocado em banho de areia em vez de béquer de platina sobre bico de bunsen. Para remoção de Ct, utilizou-se a extração com NaOH $5 \mathrm{~mol} \mathrm{~L}^{-1}$ (Norrish \& Taylor 1961). A sodalita $\left[\mathrm{Na}_{4} \mathrm{Al}_{3} \mathrm{Si}_{3} \mathrm{O}_{12}(\mathrm{OH})\right]$ formada durante $\mathrm{O}$ tratamento com NaOH $5 \mathrm{~mol} \mathrm{~L}^{-1}$ foi removida com duas extrações sucessivas com $\mathrm{HCl} 0,5 \mathrm{~mol} \mathrm{~L}^{-1}$ (Norrish \& Taylor, 1961; Singh \& Gilkes, 1991). O teor total dos elementos foi calculado pela soma das concentrações obtidas nas soluções de $\mathrm{NaOH}$ $5 \mathrm{~mol} \mathrm{~L}^{-1} \mathrm{e} \mathrm{HCl} 0,5 \mathrm{~mol} \mathrm{~L}^{-1}$. 
A mica e demais minerais 2:1 foram extraídos com $\mathrm{NaHSO}_{4}$ na forma de cristais, segundo método proposto por J ackson et al. (1986), com algumas adaptações. Cadinhos de sílica vítrea (quartzo fundido) com tampas em rosca aqueci dos em bico de bunsen foram substituídos por béqueres de teflon com tampa apenas apoiada em banho de areia. Foi colocado cerca de 0,2 g do resídu o seco obtido após o tratamento com NaOH $5 \mathrm{~mol} \mathrm{~L}^{-1}$ num béquer de teflon de $150 \mathrm{~mL}$ e adicionados $15 \mathrm{~g}$ de $\mathrm{NaHSO}_{4}$ na forma de cristais. A pós homogeneização dos cristais com a amostra, o béquer foi tampado e levado ao banho de areia. I nicialmente manteve-se a temperatura mais baixa (em torno de $200^{\circ} \mathrm{C}$ ) pela fervura intensa da suspensão durante os primeiros $25 \mathrm{~min}$. A fervura tornou-se branda após $40 \mathrm{~min}$ de reação e, com os aumentos progressivos, a temperatura alcançou $250^{\circ} \mathrm{C}$. Em seguida, os béqueres permaneceram no banho de areia por mais $2 \mathrm{~h}$ a uma temperatura de $270^{\circ} \mathrm{C}$. No final da reação (após 2 h e 40 min), a mistura transformou-se num resíduo seco bastante endurecido. A dissolução do resíduo foi feita mediante três lavagens com $\mathrm{HCl} 3 \mathrm{~mol} \mathrm{~L}^{-1}$. A primeira lavagem foi com $40 \mathrm{~mL}$ deácido em banho de areia a $80^{\circ} \mathrm{C}$ por $1 \mathrm{~h}$ eas outras duas com $30 \mathrm{~mL}$ por 30 min cada lavagem, sob a mesma temperatura. Após a extração com $\mathrm{NaHSO}_{4}$, a dissolução final do resíduo (extração de fel dspato, quartzo e minerais resistentes como rutilo e anatásio) foi feita medianteo uso de HF concentrado (Lim \& J ackson, 1986, com modificações).

Em relação à extração de caulinita da fração argila, foi usadoum método alternativo para a fração silte. A formação de sodalita durantea extração com $\mathrm{NaOH} 5 \mathrm{~mol} \mathrm{~L}^{-1}$ dificulta as análises químicas, haja vista que este mineral é formado com partes dos elementos liberados pela caulinita. A extração foi feita pela combinação de aquecimento da amostra a $550^{\circ} \mathrm{C}$ etratamento com $\mathrm{NaOH} 0,5 \mathrm{~mol} \mathrm{~L}^{-1}$ fervente (J ackson et al., 1986).

Microscopia eletrônica - Para visualizar possíveis minerais presentes nas frações areia esilte (amostra natural) e argila (amostra desferrificada) em quantidades muito pequenas a ponto de não serem identificados por DRX, amostras tomadas nas profundidades de 2,1 e 5,6 m foram estudadas por microscopia el etrônica de varredura (MEV), areia e silte, e de transmissão (MET), argila (Gilkes, 1994). As amostras das frações areia e silte foram recobertas com fina película de carbono (superfície condutora) eexaminadas em aparel hoJ EOL modelo J XA-840, acoplado com detector de raios-X por dispersão de energia (EDS), para análise química de partículas individuais. O aparel ho foi operado a 20 kV e a análise elementar semiquantitativa foi realizada, utilizando o programa LINK-AN 10.000. J á para a fração argila, utilizou-se um aparel ho PHILIPS modelo EM 400T, também acoplado com EDS, operado a $120 \mathrm{kV}$.

\section{RESULTADOS E DISCUSSÃO}

\section{Características morfológicas e físicas}

Observou-se grande variação de cor entre os horizontes do solo (Quadro 1). Os horizontes B e BC apresentaram matiz 10YR e o horizonte C coloração mais avermel hada, com matiz 5YR entre as profundidades de 2,1 e 4,9 m. Dada a maior proximidade do lençol freático, a partir de 5,6 m, as condições de maior umidade favoreceram a redução e segregação do Fe, condicionando uma coloração variegada dos sedimentos. Na maior profundidade, a matriz do sedimento apresentou coloração totalmente branca pela presença de Ct (cor neutra, N 8/) com pontos rosados (2,5YR 8/4). Segundo Duarte et al. (2000), o processo de dissolução da hematita nos sedimentos do Grupo Barreiras está ocorrendo, praticamente, em todos os ambientes dos Tabuleiros Costeiros.

Até à profundidade de $14 \mathrm{~m}$, verificou-se a formação de três camadas enriqueci das com concreções de Fe visualizadas em campo e em laboratório por observações visuais e por meio de Iupa na fração areia, compreendendo as amostras 3 e 4, 6 e 7, 9 e 10 (Quadro 1 e Figura 1). Contudo, a concentração máxima destas concreções foi observada nas profundidades de 2,1;4,2 e 7,7 m. As concreções apresentaram diâmetro superior a $1 \mathrm{~cm}$ e cor vermel ho-escura a lilás com fino recobrimento amarelo. Concreções com feições semelhantes em solos desenvolvidos de sedimentos do Grupo Barreiras foram descritas por Amador (1982), e Duarte et al. (2000). Seriam necessários estudos sedimentológi cos, incluindo a micromorfologia, para determinar se a formação destas camadas foi pedogênica (migração de ferro no pacote sedimentar pela ocorrência de diferentes regimes de umidade ao longo dos sedimentos) ou litogênica (deposição de camadas mais ricas em ferro nas profundidades de 2,$1 ; 4,2$ e 7,7 m). Segundo Amador (1982), é comuma presença de estratos laterizados vermel hoescuros a lilás, com até 4,0 m deespessura, em vários níveis de sedimentação. Esses estratos têm, de acordo com o mesmo autor, caráter tanto diagenético como pós-diagenético.

Em geral, as amostras apresentaram mais de $500 \mathrm{~g} \mathrm{~kg}^{-1}$ de argila, com pequena participação de silte (Quadro 1). Na profundidade de 7,7 m, verificou-se a deposição de uma camada mais arenosa (711 g kg-1 de areia). De acordo com a relação areia fina/areia grossa, percebeu-se que a deposição nesta camada foi preferencialmente de areia grossa. Nas demais profundidades, verificouse também o predomínio de areia grossa em relação à areia fina. O predomínio de areia grossa também foi observado por outros autores em solos desenvolvidos de sedimentos do Grupo Barreiras (Silva \& Ribeiro, 1997; Abrahão et al., 1998). 
Quadro 1. Características morfológicas e análise textural do pacote de sedimentos do Grupo Barreiras no município de Aracruz (ES)

\begin{tabular}{|c|c|c|c|c|c|c|c|c|c|c|}
\hline \multirow{2}{*}{ Amostra } & \multirow{2}{*}{ Profundidade } & \multirow{2}{*}{ Cor seco (Munsell) } & \multirow{2}{*}{ Concreção(1) } & \multicolumn{5}{|c|}{ Fração } & \multirow{2}{*}{$\begin{array}{l}\text { Classificação } \\
\text { textural }\end{array}$} & \multirow{2}{*}{ AF/AG } \\
\hline & & & & Argila & Silte & $\mathbf{A F}$ & AG & AT & & \\
\hline & $\mathrm{m}$ & & & $\underline{-}$ & - & $\mathrm{kg}^{-1}$ & 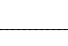 & - & & \\
\hline 1 & 0,7 & $10 Y R \quad 7 / 4$ & & 463 & 52 & 133 & 352 & 485 & $\begin{array}{l}\text { Argilo- } \\
\text { arenosa }\end{array}$ & 0,378 \\
\hline 2 & 1,4 & $10 Y R 8 / 4$ & & 548 & 66 & 107 & 279 & 386 & Argila & 0,383 \\
\hline 3 & 2,1 & $5 Y R \quad 7 / 4$ & Concreções de Fe & 572 & 58 & 91 & 279 & 370 & Argila & 0,326 \\
\hline 4 & 2,8 & $5 Y R 7 / 8$ & Concreções de Fe & 551 & 61 & 90 & 298 & 388 & Argila & 0,302 \\
\hline 5 & 3,5 & $5 Y R 7 / 6$ & & 494 & 21 & 96 & 390 & 486 & $\begin{array}{l}\text { Argilo- } \\
\text { arenosa }\end{array}$ & 0,246 \\
\hline 6 & 4,2 & $5 Y R 7 / 6$ & Concreções de $\mathrm{Fe}$ & 547 & 33 & 111 & 309 & 420 & Argila & 0,359 \\
\hline 7 & 4,9 & $5 Y R 8 / 4$ & Concreções de Fe & 542 & 39 & 129 & 290 & 419 & Argila & 0,445 \\
\hline 8 & 5,6 & $\begin{array}{l}\text { Variegada } 2,5 Y R \text { R/4 e } \\
7,5 Y R 8 / 1\end{array}$ & & 574 & 7 & 109 & 310 & 419 & Argila & 0,352 \\
\hline 9 & 7,7 & $5 Y R 8 / 4$ & Concreções de Fe & 266 & 23 & 91 & 620 & 711 & $\begin{array}{l}\text { Franco-argilo- } \\
\text { arenosa }\end{array}$ & 0,147 \\
\hline 10 & 10,5 & $\begin{array}{l}\text { Variegada } 2,5 Y R \text { R } 8 / 4 \text { e } \\
7,5 Y R 8 / 1\end{array}$ & Concreções de Fe & 527 & 14 & 86 & 373 & 459 & Argila & 0,231 \\
\hline 11 & 14,0 & $\begin{array}{l}\text { Variegada } 2,5 Y \mathrm{R} 8 / 4 \mathrm{e} \\
\mathrm{N} 8 /\end{array}$ & & 669 & 4 & 58 & 269 & 327 & Argila & 0,216 \\
\hline
\end{tabular}

(1) Descrição morfológica, segundo Lemos \& Santos (1996). Amostras 3, 6 e 9: concreções de Fe muito freqüente grande dura irregular vermelho-escura a lilás. Amostras 4, 7 e 10: concreções de Fe freqüente grande dura irregular vermelho-escura a lilás. ${ }^{(2)}$ AF areia fina, AG - areia grossa e AT - areia total.

\section{Mineralogia da fração areia}

A fração areia apresentou mineralogia uniforme, composta quase que exclusivamente de quartzo, em grãos predominantemente subangulares, com brilho graxo, a maioria com recobrimento de ferro (observações por meiodelupa). A homogeneidademineralógica, o predomínio de quartzo e a presença de concreções ferruginosas na fração areia também foram reportados por J acomine (1974), Achá Panoso (1976), Embrapa $(1978,1996)$ e Duarte et al. $(2000)$ em solos desenvolvidos de sedimentos do Grupo Barreiras.

Nos difratogramas de raios- $X$ da fração areia moída, para as amostras 4, 5, 8 e 9, notaram-se reflexões discretas de $\mathrm{Ct}$ e, para as amostras 3, 6 e 7 , além da Ct, pequena quantidade de hematita $(\mathrm{Hm})$ (Figura 2a). As demais amostras apresentaram apenas reflexões de quartzo. A presença de $\mathrm{Ct}$ foi confirmada por observações com lupa e MEV, em que o mineral aparece na forma de agregados, juntamentecom óxidos deFe(Quadro 2 eFigura 3b). Mel o et al. (2000) também observaram, por meio de DRX e microscopia eletrônica, agregados bastante estáveis de Ct na fração areia de diferentes classes de solos do Brasil. Segundo esses autores, a composição química $(\mathrm{ki}=2,08)$ e a presença de camadas no interior do mineral evidenciam que as partículas são agregados de Ct.

No presente estudo, com utilização de lupa, foi possível selecionar outros minerais na fração areia, tais como: biotita e agregados de sílica e de Ti e Fe, para serem estudados por MEV (Quadro 2 e Figura 3). Partículas de biotita, mesmo em pequena quantidade, constituem importante reserva de $\mathrm{K}$ e Mg para a fração areia. Unamba-Oparah (1985), trabal hando com sol os al tamente intemperizados da Nigéria, verificou que grande parte da reserva de K dos sol os nas frações areia fina e silte era devida à presença de partículas de mica.

\section{Mineralogia da fração argila}

A quantidade dealumínio eóxidos de Fe de baixa cristalinidade (OA) e deóxidos de Fe mais cristal inos (DCB) foi relativamente baixa (Quadro3). Os maiores teores de material de baixa cristalinidade foram verificados para as amostras mais superficiais, provavelmente, pelo efeito da matéria orgânica no favorecimento destas formas em detrimento das formas mais cristalinas (Kämpf \& Schwertmann, 1983; Carvalho Filho, 1989). O material extraído pelo OA é constituído, em grande parte, por óxidos de Al menos cristalinos (Melo, 1998). Os teores de goethita (Gt) e Hm (Quadro 4) foram obtidos com base nos teores de $\mathrm{Fe}_{2} \mathrm{O}_{3}-\mathrm{DCB}$ e na relação $\mathrm{Gt}$ / (Gt $+\mathrm{Hm})$, calculada a partir da área dos picos dos minerais nos difratogramas de raios-X (Torrent $\&$ Cabedo, 1986). Os teores de Gt, principal óxido de Fe dos sedimentos, diminuíram consistentementeem profundidade. Os teores de $\mathrm{Hm}$ foram extremamente baixos, com ligeiro aumento apenas nas camadas de concentração de Fe $(2,1 ; 4,2$ e 7,7 m). A cor amarelada dos horizontes B eBC do solo (matiz 


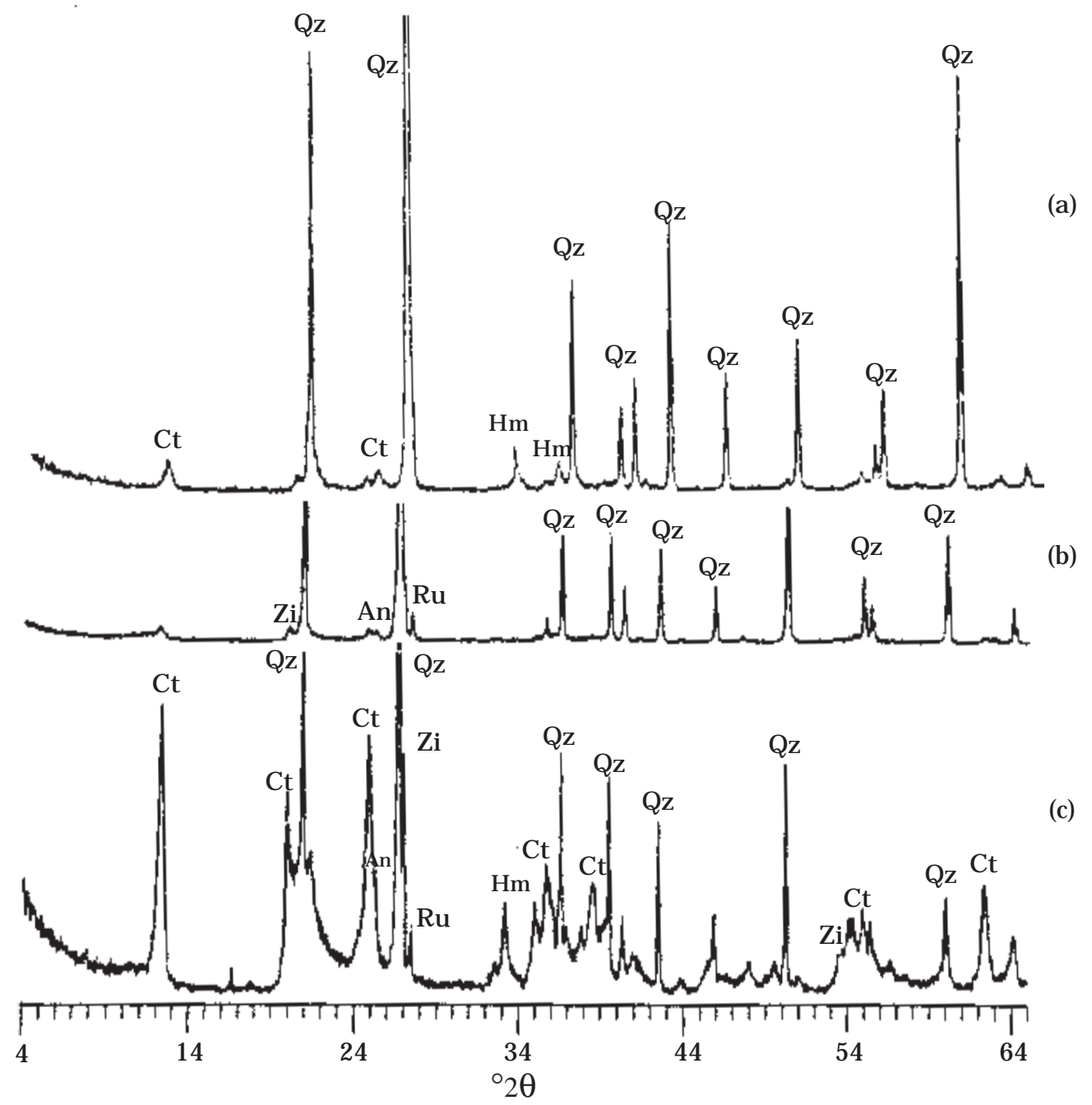

Figura 2. Difratograma de raios-X da fração areia moída (pó) na profundidade de 2,1 m (a) e da fração silte (pó) nas profundidades de 0,7 m (b) e 2,8 m (c) em sedi mentos do Grupo Barreiras no município de Aracruz (ES). Qz - quartzo, Ct - caulinita, Hm - hematita, An - anatásio, Ru - rutilo e Zi - zircão.

Quadro 2. Microanálise (EDS) de partículas individuais presentes nas frações areia, silte e argila de amostras de sedimentos do Grupo Barreiras no município de Aracruz (ES), nas profundidades de 2,1 e $5,6 \mathrm{~m}^{(1)}$

\begin{tabular}{|c|c|c|c|c|c|c|c|c|c|c|c|}
\hline Amostra & Profundidade & Partícula & Figura & $\mathrm{SiO}_{2}$ & $\mathrm{Al}_{2} \mathrm{O}_{3}$ & $\mathrm{Fe}_{2} \mathrm{O}_{3}$ & $\mathrm{TiO}_{2}$ & $\mathrm{~K}_{2} \mathrm{O}$ & MgO & CaO & $\mathrm{Na}_{2} \mathrm{O}$ \\
\hline & $\mathrm{m}$ & & & \multicolumn{8}{|c|}{$\mathrm{g} \mathrm{k} \mathrm{k}^{-1}$} \\
\hline $3(2)$ & 2,1 & Biotita & $3 a$ & 415 & 163 & 159 & 49 & 69 & 136 & 0 & 10 \\
\hline $3^{(2)}$ & 2,1 & Agregado Ct/Fe & $3 b$ & 462 & 383 & 128 & 19 & 0 & 2 & 0 & 6 \\
\hline $3^{(2)}$ & 2,1 & Agregado de sílica & & 968 & 22 & 3 & 0 & 0 & 2 & 0 & 5 \\
\hline $8^{(2)}$ & 5,6 & Agregado de sílica & $3 c$ & 993 & 4 & 0 & 1 & 0 & 0 & 0 & 1 \\
\hline $8^{(2)}$ & 5,6 & Óx. Ti e Fe & $3 d$ & 13 & 14 & 322 & 644 & 1 & 2 & 0 & 4 \\
\hline $3^{(3)}$ & 2,1 & Biotita & & 406 & 208 & 148 & 36 & 39 & 129 & 6 & 14 \\
\hline $8^{(3)}$ & 5,6 & Biotita & & 419 & 241 & 179 & 1 & 31 & 120 & 1 & 7 \\
\hline $8^{(4)}$ & 5,6 & Biotita & $3 e$ & 419 & 237 & 165 & 17 & 81 & 55 & 8 & nd \\
\hline
\end{tabular}

(1) Dados médios normalizados. Agregado Ct/Fe - agregado de caulinita e óxido de ferro, Óx. Ti e Fe - óxido deTi e Fe. ${ }^{(2)}$ Fração areia. (3) Fração silte. ${ }^{(4)}$ fração argila. nd, não determinado. Na figura 3, são apresentadas fotomicrografias de algumas partículas deste quadro. 


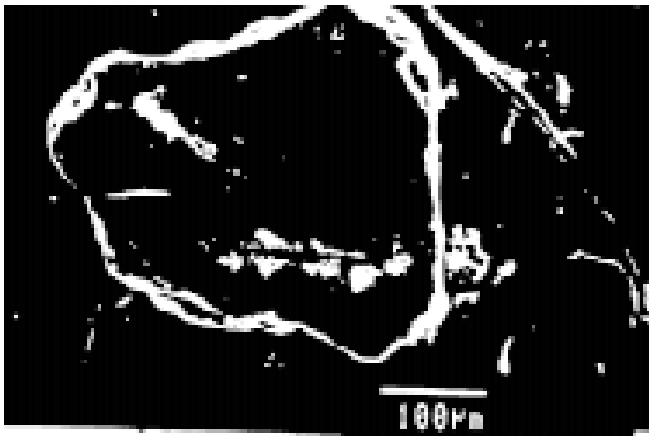

(a)

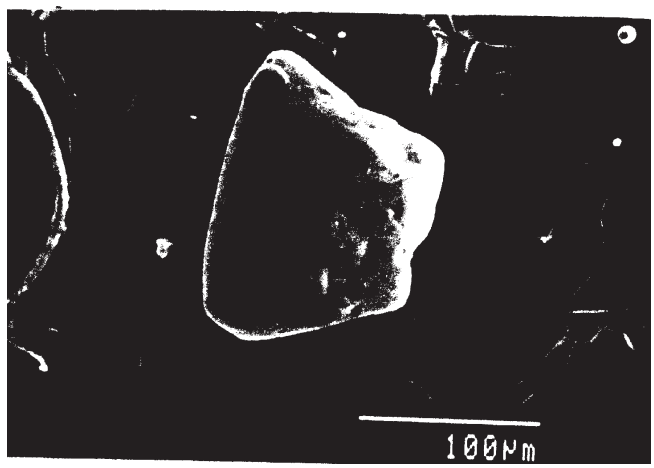

(c)

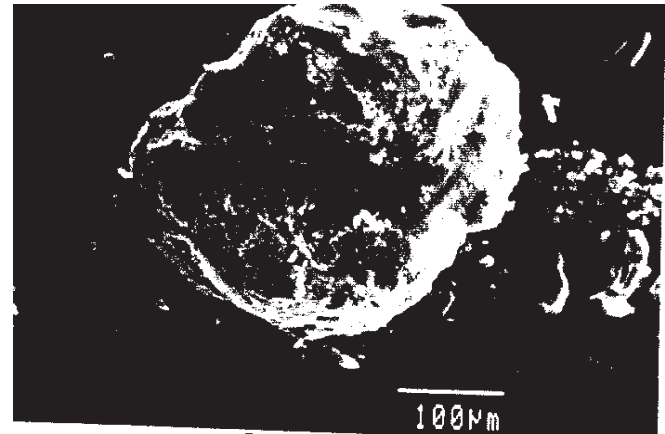

(b)

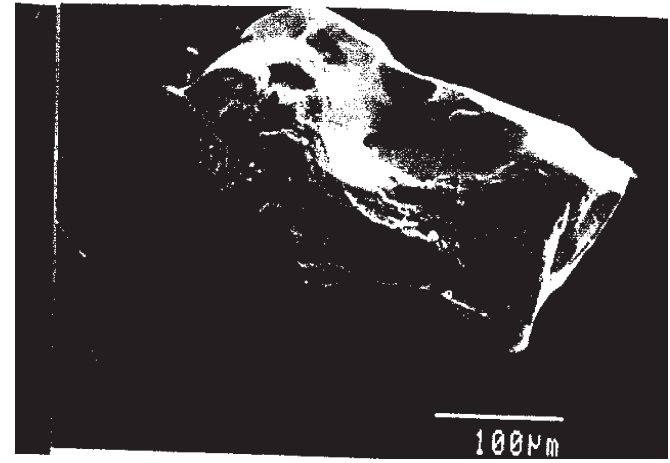

(d)

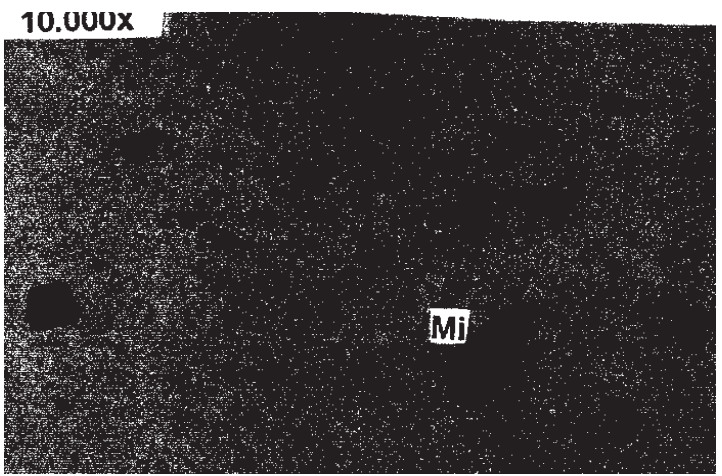

(e)

Figura 3. Fotomicrografias (MEV) de partículas de biotita (a), agregado de caulinita e óxido de ferro (b), agregado de sílica (c) e óxido de Ti e Fe (d) na fração areia na profundidade de $2,1 \mathrm{~m}$ e partícula de biotita (e) na fração argila (MET) na profundidade de 5,6 m, em sedimentos do Grupo Barreiras no município de Aracruz (ES).

10YR, Quadro 1) foi atribuída à virtual ausência de $\mathrm{Hm}$ nas profundidades de 0,7 e 1,4 m (Quadro 4).

No caso da extração com NaOH $0,5 \mathrm{~mol} \mathrm{~L}^{-1}$, mesmo aumentando a relação argila:solução, proposta por J ackson et al. (1986), de 0,1 g:100 mL para 0,4 g:100 mL, verificou-se a remoção de Ct. A proporção de material extraído da fração argila pelo tratamento variou de 95 a $127 \mathrm{~g} \mathrm{~kg}^{-1}$ (Quadro 3). Desse total, a percentagem de Ct de menor cristal inidade extraída variou de 96,3 a 99,4\%. Como resultado, apenas uma pequena fração do material extraído pelo $\mathrm{NaOH} \quad 0,5 \mathrm{~mol} \mathrm{~L}^{-1}$ foi atribuída à remoção de alumina, sílica e aluminossilicato de baixa cristalinidade (Quadro 4). A proporção de Ct removida pelo tratamento foi calculada pela diferença entre o teor do mineral antes e depois do tratamento, com base nos diagramas da ATGD. Outra constatação da extração de $\mathrm{Ct}$ foi a relação molar $\mathrm{SiO}_{2} / \mathrm{Al}_{2} \mathrm{O}_{3}$ do material extraído pelo $\mathrm{NaOH}$ $0,5 \mathrm{~mol} \mathrm{~L}^{-1}$, que variou de 1,85 a 1,98. De acordo com J ackson et al . (1986), valores entre 1,5 e 2,3 são atribuídos à remoção de Ct de menor cristalinidade. Melo et al. (2001b) observaram que a Ct presente na fração argila de diferentes classes de solos do 
Quadro 3. Contribuição das extrações seqüenciais no peso da fração argila e silte de amostras de sedimentos do Grupo Barreiras no município de Aracruz (ES), em diferentes profundidades ${ }^{(1)}$

\begin{tabular}{|c|c|c|c|c|c|c|c|c|c|c|}
\hline \multirow{2}{*}{ Amostra } & \multirow{2}{*}{ Profundidade } & \multicolumn{6}{|c|}{ Argila } & \multicolumn{3}{|c|}{ Silte } \\
\hline & & OA & DCB & $\begin{array}{c}\mathrm{NaOH} \\
0,5 \mathrm{~mol} \mathrm{~L}^{-1}\end{array}$ & $\begin{array}{c}\mathrm{NaOH} \\
5 \mathrm{~mol} \mathrm{L-1}\end{array}$ & $\mathrm{NaHSO}_{4}$ & HF & Aq. + NaOH & $\mathrm{NaHSO}_{4}$ & HF \\
\hline & $\mathrm{m}$ & & & & & $-\mathrm{g} \mathrm{kg}^{-1}$ & & & & \\
\hline 1 & 0,7 & 24,0 & 72,5 & 95,0 & 764,0 & 33,3 & 11,2 & 123,6 & 121,1 & 755,3 \\
\hline 2 & 1,4 & 25,7 & 72,3 & 127,0 & 737,2 & 28,7 & 9,0 & 252,0 & 65,7 & 682,3 \\
\hline 3 & 2,1 & 20,9 & 71,3 & 117,9 & 757,3 & 24,1 & 8,6 & 417,6 & 134,6 & 447,8 \\
\hline 4 & 2,8 & 20,5 & 58,2 & 119,9 & 763,1 & 30,7 & 7,6 & 505,2 & 93,2 & 401,6 \\
\hline 5 & 3,5 & 14,9 & 34,2 & 125,1 & 777,9 & 37,0 & 10,8 & 388,8 & 71,4 & 539,8 \\
\hline 6 & 4,2 & 17,6 & 48,0 & 120,2 & 772,7 & 31,5 & 10,0 & 328,5 & 238,2 & 433,4 \\
\hline 7 & 4,9 & 7,8 & 39,6 & 109,9 & 800,3 & 32,4 & 10,0 & 357,2 & 231,1 & 411,6 \\
\hline 8 & 5,6 & 3,3 & 20,7 & 122,7 & 812,1 & 31,3 & 9,9 & 219,2 & 137,0 & 643,8 \\
\hline 9 & 7,7 & 4,0 & 45,2 & 103,7 & 812,4 & 24,8 & 9,9 & 253,9 & 312,6 & 433,5 \\
\hline 10 & 10,5 & 3,3 & 30,4 & 103,9 & 824,1 & 29,5 & 8,8 & 318,6 & 230,7 & 450,7 \\
\hline 11 & 14,0 & 3,2 & 13,7 & 96,6 & 824,6 & 42,0 & 19,9 & 420,3 & 64,6 & 515,1 \\
\hline
\end{tabular}

(1) Extrações seqüenciais: fração argila - OA, oxalato de amônio, DCB, ditionito-citrato-bicarbonato, $\mathrm{NaOH}^{0,5} \mathrm{~mol} \mathrm{~L}^{-1}$, $\mathrm{NaOH} 5 \mathrm{~mol} \mathrm{~L}^{-1}, \mathrm{NaHSO}_{4}$ e $\mathrm{HF}$ concentrado. Fração silte - aquecimento a $550^{\circ} \mathrm{C}$ por quatro horas e extração com $\mathrm{NaOH} 0,5 \mathrm{~mol} \mathrm{~L}^{-1}$, $\mathrm{NaHSO}_{4}$ e HF concentrado.

Quadro 4. Mineralogia da fração argila e silte de amostras de sedimentos do Grupo Barreiras no município de Aracruz (ES), em diferentes profundidades ${ }^{(1)}$

\begin{tabular}{|c|c|c|c|c|c|c|c|c|c|c|c|c|c|c|c|c|}
\hline \multirow{3}{*}{ Amostra } & \multirow{3}{*}{ Profundidade } & \multicolumn{8}{|c|}{ Argila } & \multicolumn{7}{|c|}{ Silte } \\
\hline & & \multirow{2}{*}{$\mathbf{C t}$} & \multicolumn{2}{|c|}{ Amorfo } & \multirow{2}{*}{ Hm } & \multirow{2}{*}{ Gt } & \multirow{2}{*}{ An } & \multirow{2}{*}{ Mi } & \multirow{2}{*}{ Total } & \multirow{2}{*}{$\mathbf{C t}$} & \multirow{2}{*}{ Hm } & \multirow{2}{*}{ An } & \multirow{2}{*}{$\mathbf{Z i}$} & \multirow{2}{*}{ Mi } & \multirow{2}{*}{ Total } & \multirow{2}{*}{ Qz } \\
\hline & & & OA & NaOH & & & & & & & & & & & & \\
\hline & $\mathrm{m}$ & & & & & & & & $\mathrm{g} \mathrm{kg}^{-1}$ & & & & & & & \\
\hline 1 & 0,7 & 870 & 24 & 4 & 0 & 60 & 24 & 1,1 & 982 & 123 & 22 & 27 & 0,3 & 1,3 & 174 & 826 \\
\hline 2 & 1,4 & 884 & 26 & 3 & 3 & 55 & 23 & 0,8 & 994 & 244 & 27 & 25 & 0,2 & 1,4 & 298 & 702 \\
\hline 3 & 2,1 & 872 & 21 & 3 & 8 & 45 & 23 & 0,8 & 972 & 413 & 137 & 29 & 0,2 & 2,6 & 582 & 418 \\
\hline 4 & 2,8 & 893 & 21 & 3 & 9 & 32 & 25 & 1,4 & 984 & 503 & 101 & 43 & 0,2 & 2,4 & 650 & 350 \\
\hline 5 & 3,5 & 900 & 15 & 2 & 8 & 19 & 30 & 1,9 & 976 & 378 & 71 & 59 & 0,3 & 2,7 & 511 & 489 \\
\hline 6 & 4,2 & 903 & 18 & 3 & 15 & 21 & 27 & 2,2 & 989 & 307 & 221 & 47 & 0,4 & 2,3 & 578 & 422 \\
\hline 7 & 4,9 & 899 & 8 & 2 & 11 & 17 & 28 & 2,6 & 967 & 344 & 194 & 66 & 0,5 & 2,5 & 607 & 393 \\
\hline 8 & 5,6 & 934 & 3 & 2 & 5 & 7 & 24 & 3,1 & 978 & 218 & 81 & 79 & 0,6 & 2,5 & 381 & 619 \\
\hline 9 & 7,7 & 905 & 4 & 2 & 18 & 21 & 22 & 2,5 & 974 & 238 & 257 & 48 & 0,3 & 2,3 & 546 & 454 \\
\hline 10 & 10,5 & 936 & 3 & 1 & 14 & 5 & 22 & 2,6 & 983 & 314 & 236 & 61 & 0,5 & 1,9 & 613 & 387 \\
\hline 11 & 14,0 & 953 & 3 & 1 & 3 & 1 & 17 & 4,3 & 983 & 396 & 79 & 61 & 0,5 & 2,2 & 539 & 461 \\
\hline
\end{tabular}

(1) Ct, caulinita; amorfo, material amorfo extraído pelo oxalato de amônio (OA) e pelo NaOH 0,5 mol L-1; Hm, hematita; Gt, goethita; An, anatásio; Zi, zircão; Mi, mica. Qz na fração silte, $1.000 \mathrm{~g} \mathrm{~kg}^{-1}$ - total.

Brasil apresentou baixo grau de cristalinidade, favorecendo a sua dissolução pela solução de $\mathrm{NaOH}$ $0,5 \mathrm{~mol} \mathrm{~L}^{-1}$ fervente.

O método proposto por J ackson (1979) eJ ackson et al. (1986) para remoção de alumina, sílica e aluminossilicatos de baixa cristalinidade mostrou-se inadequado para solos e sedimentos desenvolvidos sob condições tropicais úmi das. Duarte et al. (2000), utilizando a relação solo:solução de 0,1g:100 mL, encontraram teores de "sílica amorfa" em alguns sol os do Grupo Barreiras, no mesmo município deste trabal ho, da ordem de $27,5 \mathrm{~g} \mathrm{~kg}^{-1}$. 
No presente estudo, a quantidade de aluminossilicato de baixa cristalinidade na fração argila nas diferentes profundidades foi bem menor, variando de 1 a $4 \mathrm{~g} \mathrm{~kg}^{-1}$ (Quadro 4). A pequena quantidade de material extraído pelo $\mathrm{OA}$ e $\mathrm{NaOH} 0,5 \mathrm{~mol} \mathrm{~L}^{-1}$ fervente foi atribuída ao el evado grau de desenvolvimento dos sedimentos. Por outro lado, Melo (1998) verificou quesol os jovens desenvolvidos de granito e gnaisse continham maiores teores de material de baixa cristalinidade, apresentando a fração argila do horizonte $C$ de um Argissolo Vermel ho-Amarelo do município de Aracruz (ES) teor de material extraído pelo OA igual a $280 \mathrm{~g} \mathrm{~kg}^{-1}$.

$O$ baixo teor de minerais ferromagnesianos no material, granito e gnaisse leuco e mesocrático, que deu origem aos sedimentos, a abundância dessas rochas em feldspatos e a possibilidade de transformação dir reta destemineral em Ct sob clima tropical (Grant, 1964; Anand et al., 1985), o al to grau de intemperismo ocorrido antes da deposição e as condições úmidas dos Tabuleiros Costeiros favoreceram a concentração de Ct e a remoção de minerais, principalmente, óxidos de Fe (Melo et al. 2001a). O teor de Ct na fração argila dos sedimentos atingiu $953 \mathrm{~g} \mathrm{~kg}^{-1}$ a $14 \mathrm{~m}$ de profundidade (Quadro 4). A ausência de reflexão em 0,72 nm confirmou que toda a Ct foi removida pelo tratamento com NaOH $5 \mathrm{~mol} \mathrm{~L}^{-1}$ fervente(Figura 4). A Ct foi estimada com base nos diagramas da ATGD, e a ausência de gibbsita foi confirmada por DRX e ATD. Duarte et al. (2000), utilizando o mesmo método de determinação, obtiveram teores de Ct na fração argila de solos do Grupo Barreiras variando de 810 a $890 \mathrm{~g} \mathrm{~kg}^{-1}$.

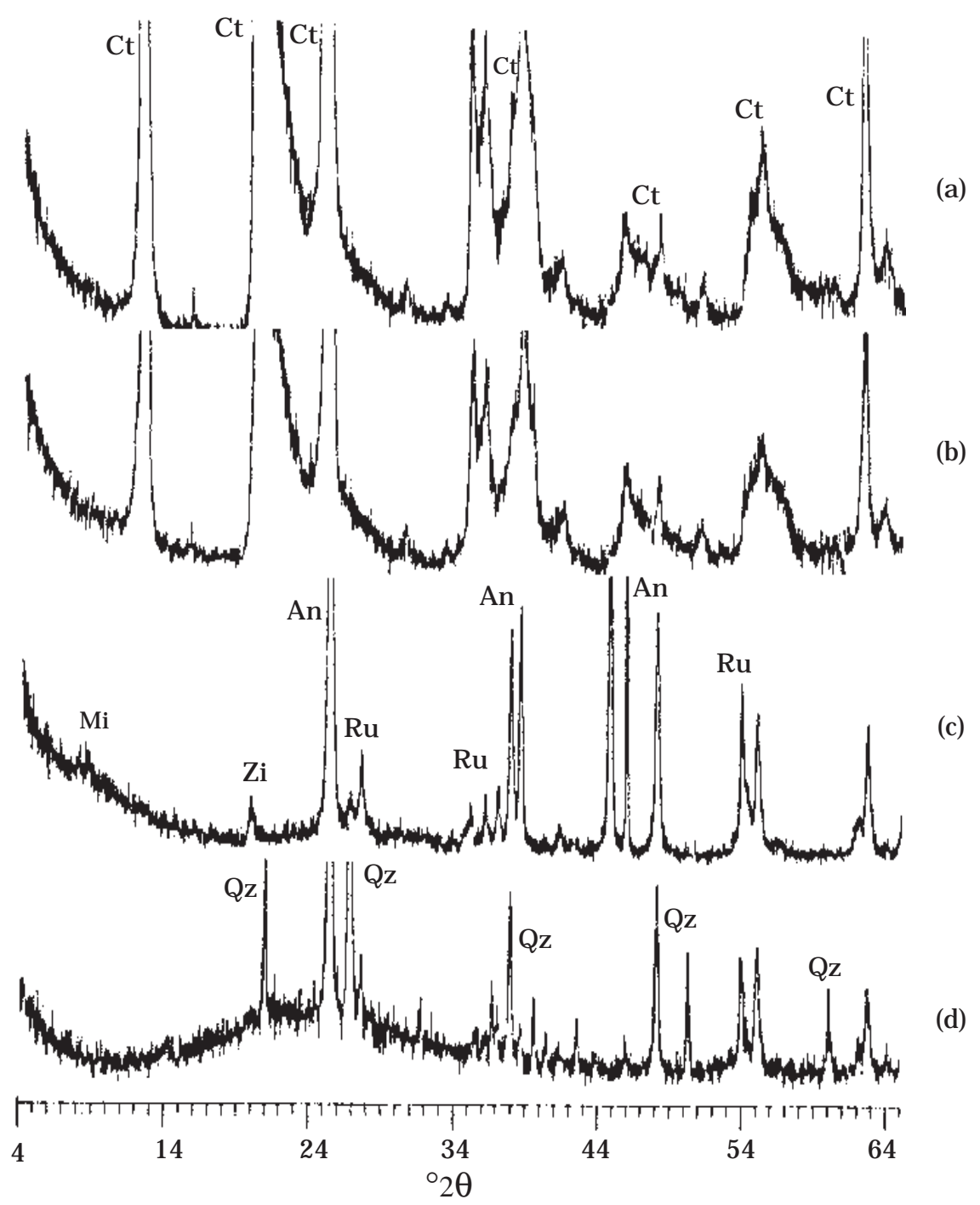

Figura 4. Difratogramas de raios-X da fração argila (amostra orientada) na profundidade de $14 \mathrm{~m}$ em sedimentos do Grupo Barreiras no município de Aracruz (ES), mostrando a mineralogia com os tratamentos seqüenciais (a) sem tratamento, (b) após DCB, (c) após $\mathrm{NaOH} 5 \mathrm{~mol} \mathrm{~L}^{-1}$ fervente e (d) após $\mathrm{NaHSO}_{4}$ : Ct - caulinita, Mi - mica, Zi - zircão, An - anatásio, Ru - rutilo e Qz - quartzo. 
Apesar de o tratamento com $\mathrm{NaHSO}_{4}$ ser usado para remoção de mica e outros minerais do tipo 2:1 (J ackson et al., 1986), os minerais deTi, principalmente anatásio (com base nos difratogramas de raios- $X$, Figura 4) foram preferencialmente dissolvidos. Os teores de $\mathrm{TiO}_{2}$ representaram 724 a $818 \mathrm{~g} \mathrm{~kg}^{-1}$ de elementos extraídos pelo tratamento. A proporção de mica na fração argila (Quadro 4) foi estimada com base no K extraído pelo $\mathrm{NaHSO}_{4}$ eadmitindo-se um teor médio de $100 \mathrm{~g} \mathrm{~kg}^{-1}$ de $\mathrm{K}_{2} \mathrm{O}$ neste mineral (J ackson, 1979). Como observado para a Ct, os teores de mica aumentaram em profundidade. O maior acúmulo de $\mathrm{Si}, \mathrm{K}$ e outros íons em solução, considerando as condições de drenagem, tornou o ambiente menos favorável ao intemperismo dos minerais mi cáceos, comparado com as camadas mais superficiais. Uma evidência deste acúmulo de íons nas maiores profundidades foi a necessidade de adi ção de solução hexametafosfato de $\mathrm{Na}(5 \%$ p/v) a partir da profundidade de 4,9 m para viabilizar a dispersão das frações argila esilte. Os baixos teores de minerais micáceos na fração argila (máximo de $4,3 \mathrm{~g} \mathrm{~kg}^{-1}$ ) são explicados pel o avançado estádio de intemperismo e maturidade dos sedimentos. Duarte et al. (2000) também observaram, por meio de DRX, pequena quantidade de mica na fração argila de alguns solos do Grupo Barreiras.

Mesmo após a remoção dos óxidos de Fee Ct, não foi detectada mica nos difratogramas de raios-X. Apenas para a profundidade de $14 \mathrm{~m}$, verificou-se o aparecimento de discreta reflexão a $1,0 \mathrm{~nm}$ (Figura 4). Contudo, percebeu-se a presença de partículas de mica por MET eEDS na profundidade de 5,6 m (Quadro 2 e Figura 3e).

Como observado para o tratamento com $\mathrm{NaHSO}_{4}$, o resíduo extraído pelo HF na extração seqüencial representou apenas uma pequena proporção da fração argila (7,6 a 19,9 $\mathrm{g} \mathrm{kg}^{-1}$, Quadro 3), sendo constituído, principalmente, por anatásio (734 a $891 \mathrm{~g} \mathrm{~kg}^{-1}$ de el ementos determinados no extrato do $\mathrm{HF}$ era constituído de $\mathrm{TiO}_{2}$ ). Não foi possível quantificar o quartzo extraído pelo HF em decorrência da perda de $\mathrm{SiO}_{2}$ durante a digestão, na forma de gás $\mathrm{SiF}_{4}$ (Lim \& J ackson, 1986). Contudo, a presença de quartzo ficou evidente nos difratogramas de raios-X (Figura 4). Em virtude da pequena quantidade de quartzo, as reflexões do mineral apenas tornaram-se visíveis após a remoção de óxidos de $\mathrm{Fe}$, Ct e parte dos óxidos deTi. Mesmo sendo um mineral solúvel na fração argila, Melo (1998) também identificou (DRX e MET) e analisou (EDS) partículas de quartzo em vários Latossolos do Brasil.

O teor de anatásio na fração argila foi baixo (Quadro 4). A proporção do mineral foi obtida pela alocação dos teores totais de Ti extraídos pelo HF em amostra de argila natural (sem tratamento). A pequena diferença entre $1.000 \mathrm{~g} \mathrm{~kg}^{-1} \mathrm{e}$ a soma dos minerais determinados pode ser devida à presença de quartzo e outros minerais não identificados.

\section{Mineralogia da fração silte}

$\mathrm{O}$ aquecimento a $550^{\circ} \mathrm{C}$ por $4 \mathrm{~h}$ provocou uma redução de peso da amostra em decorrência da perda da água adsorvida entre 105 e $350^{\circ} \mathrm{C}$ e da desidroxilação da Ct. Deacordo comJ ackson (1979), a Ct padrão apresenta $140 \mathrm{~g} \mathrm{~kg}^{-1}$ deágua estrutural, na forma de hidroxila. Com a perda de água, a Ct transformou-se em material de baixa cristalinidade ( ackson et al., 1986). A remoção restante deveu-se ao tratamento com $\mathrm{NaOH} 0,5 \mathrm{~mol} \mathrm{~L}^{-1}$ que promoveu a extração da Ct amorfa desidratada, liberando Si, Al e demais el ementos constituintes (J ackson et al., 1986). A extração total, aquecimento a $550^{\circ} \mathrm{C}$ mais $\mathrm{NaOH} 0,5 \mathrm{~mol} \mathrm{~L}^{-1}$, encontra-se no quadro 3.

A amostra tomada à profundidade de $2,8 \mathrm{~m}$ apresentou a maior remoção por este tratamento e teor de Ct no silte (Quadros 3 e 4 e Figura 2c). Os teores de Ct foram obtidos a partir dos diagramas daATGD deamostras da fração silte. Segundo Melo (1998), utilizando MEV, a Ct na fração silte destas amostras encontrava-se na forma de agregados bastantes estáveis, uma vez que resistiram à dispersão com $\mathrm{NaOH} 0,2 \mathrm{~mol} \mathrm{~L}^{-1}$ ea vibrações ultrasônicas durante a separação das frações.

Após a extração da Ct, a fração silte foi submetida ao tratamento com $\mathrm{NaHSO}_{4}$ para extração de óxidos de $\mathrm{Fe}$, mica e demais minerais do tipo 2:1, o que resultou numa redução de peso da amostra de 64,6 a 312,6 $\mathrm{g} \mathrm{kg}^{-1}$ (Quadro 3). Tal variação foi atribuída às diferenças mineralógicas da fração silte dos sedimentos nas diferentes profundidades. As mai ores extrações foram para as profundidades com maior presença de $\mathrm{Hm}$ (Quadros 3 e 4). Como verificado para a fração argila, grande parte dos óxidos de Ti presentes na fração silte foi dissolvida pel otratamento com $\mathrm{NaHSO}_{4}$. Dototal deel ementos extraídos pelo tratamento, a participação do $\mathrm{TiO}_{2}$ (105 a $423 \mathrm{~g} \mathrm{~kg}^{-1}$ ) foi superada apenas pelo $\mathrm{Fe}_{2} \mathrm{O}_{3}$ (301 a $835 \mathrm{~g} \mathrm{~kg}^{-1}$ ).

A alta proporção de remoção pelo HF (Quadro 3) foi devida à abundância de quartzo na fração silte (Quadros 3 e Figura 2b,c). Este mineral, por ser resistenteaos tratamentos prévios, concentrou-seno resíduo após a extração com $\mathrm{NaHSO}_{4}$.

O teor de $\mathrm{Hm}$, anatásio e zircão na fração silte (Quadro 4) foi calculado com base nos teores totais de $\mathrm{Fe}$, Ti e $\mathrm{Zr}$, obtidos pela digestão da amostra natural (sem tratamento) com HF concentrado. Os maiores teores de $\mathrm{Hm}$, como observado para a fração argila, foram para as camadas enriquecidas com ferro na forma de concreções. A inexistência de Gt foi comprovada pela ausência de reflexão por DRX e do pico endotérmico característico do mineral por ATD. O teor de mica foi obtido seguindo o mesmo procedimento usado para a fração argila. Como verificado para a fração argila, os teores de mica foram inferiores a $3 \mathrm{~g} \mathrm{~kg}^{-1}$ (Quadro 4), evidenciando $\mathrm{o}$ alto grau de desenvolvimento dos sedimentos. A grande diferença entre $1.000 \mathrm{~g} \mathrm{~kg}^{-1}$ de siltee a soma 
dos minerais determinados deveu-se à abundância de quartzo na fração silte, principalmente para a profundidade de $0,7 \mathrm{~m}$. Como discutido anteriormente, nãofoi possível determinar oteor de quartzo extraído pelo HF concentrado na análise seqüencial .

\section{CONCLUSÕES}

1. As frações areia e silte do solum e do material de origem apresentaram baixos teores de minerais primários fontes de nutrientes (apenas traços de mica), com predomínio de quartzo e presença de agregados de Ct, Hm e anatásio.

2. Os teores de Ct e mica na fração argila aumentaram em profundidade, atingindo $953 \mathrm{e}$ $4,3 \mathrm{~g} \mathrm{~kg}^{-1}$, respectivamente, a $14 \mathrm{~m}$. Os baixos teores de ferro dos sedimentos e as condições úmidas dos Tabul eiros Costei ros favoreceram a concentração de Ct e a remoção de minerais, principalmente óxidos de Fe. Mesmo em baixos teores, a proporção de $\mathrm{Hm}$ e Gt na fração argila determinou a cor do solum (matiz amarelada) e do material de origem (matiz avermelhada).

3. Considerando o el evado grau de desenvolvimento dos sedimentos, a quantidade de material de baixa cristalinidade na fração argila nas diferentes profundidades foi pequena. Não é recomendável utilizar a solução de $\mathrm{NaOH} 0,5 \mathrm{~mol} \mathrm{~L}^{-1}$ fervente para extração de alumina, sílica e al uminossilicatos de baixa cristalinidade em sol os e sedimentos ondea Ct apresenta baixa cristalinidade, especialmente sob clima tropical úmido, uma vez que, nessas condi ções, o método não discrimina estas duas fases minerais.

\section{LITE RATURA CITADA}

ABRAHÃO, W.A.P.; COSTA, L.M.; MELLO, J.W. \& NEVES, J.C. Distribuição de freqüência de tamanho da fração areia e compacidade relativa de sol os desenvolvidos de sedimentos do Grupo Barreiras. R. Bras. Ci. Solo, 22:1-9, 1998.

ACHÁ PANOSO, L. Latossolo Vermelho-Amarelo de tabuleiro do Espírito Santo. Recife, Universidade Federal Rural de Pernambuco, 1976. 115p. (Tese Livre Docência)

AMADOR, E.S. O Barreiras pleistocênio no estado do Espírito Santo e seu relacionamento com depósitos de minerais pesados. In: CONGRESSO BRASILEIRO DE GEOLOGIA, 32, Salvador, 1982. Anais. Salvador, Sociedade Brasileira de Geologia, 1982. v.4. p.1462-1472.

ANAND, R.R.; GILKES, R.J .;ARMITAGE,T.M. \& HILLER,J.W. Feldspar weathering in lateritic saprolite. Clays Clay Miner. 33:31-43, 1985.

ARCANJ O,J .D. La formation Barreiras dans la region deVitoria, ES. Strasbourg, UniversitéLouis Pasteur, 1990. 110p. (Tese de Doutorado)
BIGARELA, J.J. The Barreiras Group in Northeastern Brazil. An. Acad. Bras. Ci., 47:365-393, 1975.

CARVALHO FILHO,A. Caracterização mineralógica, química e física de solos de duas unidades de paisagem do planalto de Viçosa-MG. Viçosa, Universidade Federal de Viçosa, 1989. 114p. (Tese de Mestrado)

DUARTE, M.N.; CURI, N.; PÉREZ, D.V.; KÄMPF, N. \& CLAESSEN, M.E.C. Mineralogia, química e micromorfologia de sol os de uma microbacia nos Tabuleiros Costeiros do EspíritoSanto. Pesq. Agropec. Bras., 35:12371250, 2000.

EMPRESA BRASILEIRA DE PESQUISA AGROPECUÁRIA EMBRAPA. Levantamento de reconhecimento dos solos do Estado do Espírito Santo. Rio de J aneiro, 1978. 461p. (Bol etim Técnico, 45)

EMPRESA BRASILEIRA DE PESQUISA AGROPECUÁRIA EMBRAPA. Serviço Nacional de Levantamento e Conservação de Solo. Manual de métodos de análise de sol o. Rio de janeiro, 1979. não paginado.

EMPRESA BRASILEIRA DE PESQUISA AGROPECUÁRIA EMBRAPA. Reunião técnica sobre solos coesos dos Tabuleiros Costeiros. Anais. Cruz das Almas, 1996. 80p.

EMPRESA BRASILEIRA DE PESQUISA AGROPECUÁRIA EMBRAPA. Centro Nacional de Pesquisas de Solos. Rio de J aneiro. Sistema Brasileiro de classificação de solos. Brasília, Serviço de Produção de Informação, 1999. 412p.

GEE, G.W. \& BAUDER, J.W. Particle-size analysis. In: KLUTE, A., ed. Methods of soil analysis. Parte 1: Physical and mineralogical methods. Madison, Soil Science Society of America, 1986. p.383-412.

GILKES, R.J . Transmission Electron Microscopy analysis of soil materials. Quantitative Methods in Soil Mineralogy. Madson, Soil Science Society of America, 1994. p177-204.

GRANT, W.H. Chemical weathering of biotite-plagioclase gneiss. Clays Clay Miner., 12:455-463, 1964.

HUGHES, J.C \& BROWN, G. A crystallinity index for soil kaolinite and its relation to parent rock, climate and soil maturity. J. Soil Sci., 30:557-563, 1979.

JACKSON, M.L. Soil chemical analysis - advanced course. Madison, Prentice-Hall, 1979. 895p.

JACKSON, M.L.; LIM, C.H. \& ZELAZNY, L.W. Oxides, hydroxides, and aluminosilicates. In: KLUTE, A., ed. Methods of soil analysis. Parte 1: Physical and mineralogical methods. Madison, American Society of Agronomy, 1986. p.101-150.

J ACOMINE, P.K.T. Fragipans em solos de tabuleiros: características, gênese implicações no uso agrícola. Recife, Universidade Federal Rural de Pernambuco, 1974. 112p. (Tese Livre Docência)

KÄMPF, N. \& SCHWERTMANN, U. Goethite and hematite in a climosequence in southern Brazil and their application in classification of kaolinitic soils. Geoderma, 29:27-39, 1983.

LEMOS, R.C. \& SANTOS, R.D. Manual de descrição e coleta de solos no campo. 3.ed. Campinas, Sociedade Brasileira de Ciência do Solo, 1986. 85p. 
LIM, C.H. \& JACKSON, M.L. Dissolution for total elemental analysis. In: PAGE, A.L., ed. Methods of soil analysis. Parte 2: Chemical and microbiological properties. Madison, American Society of Agronomy, 1996. p.1-12.

MABESOONE, J.M. Relief of northeastern Brazil and its correlated sediments. Zeitschrift Geom., 4:419-453, 1966.

MATTOS, C.M. Propriedades físicas de solos cauliníticos coesos do município de Aracruz, ES. Piracicaba, Escola Superior de Agricultura Luiz de Queiroz, 1979. 73p. (Tese de Mestrado)

McKEAGUE, J.A. Manual on soil sampling and methods of analysis. Ottawa, Canadian Society of Soil Sicience, 1978. 212p.

MEHRA, O.P. \& J ACKSON, M.L. I ron oxide removal from soils and clay by a dithionite-citratesystem bulfered with sodium bicarbonate. Clays Clay Miner., 7:317-327, 1960.

MELO, V.F. Potássio e magnéssio em minerais de sol os e relação entre propriedades da caulinita com formas não trocáveis destes nutrientes. Viçosa, U niversidade Federal deViçosa, 1998. 205p. (Tese de Doutorado)

MELO, V.F.; FONTES, M.P.F.; NOVAIS, R.F.; SINGH, B. \& SCHAEFER, C.E.G.R. Características dos óxidos de ferro e de alumínio de diferentes classes de solos. R. Bras. Ci. Solo, 25:19-32, 2001a.

MELO, V.F.; NOVAIS, R.F.; FONTES, M.P.F. \& SCHAEFER, C.E.G.R. Potássio e magnésio em minerais das frações areia esilte de diferentes sol os. R. Bras. Ci. Solo, 24:269:284, 2000.

MELO, V.F.; SINGH, B.; SCHAEFER, C.E.G.R.; NOVAIS, R.F. \& FONTES, M.P.F.F. Chemical and mineralogical properties of kaolinite-ricle Brazilian soils. Soil Sci. Soc. Am. J., 65:1324-1333, 2001b. (no prelo).
MELO, V.F.; SCHAEFER, C.E.G.R.; NOVAIS, R.F.; SINGH, B. \& FONTES, M.P.F. Potassium and magnesium reserve in clay minerals of some Brazilian soils, as indicated by sequential extraction procedure. Comm. Soil Sci. Plant An., 2002b. (in publication)

NORRISH, K. \& TAYLOR, M. The isomorphous replacement of iron by aluminium in soil goethites. J. Soil Sci., 12:294306, 1961.

PETRI, S. \& FÚLFARO, V. Geologia do Brasil. São Paulo, Universidade de São Paulo, 1983. 631p.

SILVA, A.J.N. \& RIBEIRO, M.R. Caracterização de Latossolo Amarelo sob cultivo contínuo de cana-de-açúcar no estado de Alagoas: atributos morfológicos e físicos. R. Bras. Ci. Solo, 21:6777-684, 1997.

SINGH, B. \& GILKES, R.J. Concentration of iron oxides from soil clays by $5 \mathrm{M} \mathrm{NaOH}$ treatment: The complete removal of sodalite and kaolin. Clay Miner., 26:463-472, 1991.

SINGH, B. \& GILKES, R.J. Properties of soil kaolinites from south-westen Australia. J. Soil Sci., 43:645-667, 1992.

TAN, K.B.; HAJEK, B.F. \& BARSHAD, I. Thermal analysis techniques. In: KLUTE, A., ed. Methods of soil analysis. Parte 1: Physical and mineralogical methods. Madison, American Society of Agronomy, 1986. p.151-183.

TORRENT, J . \& CABEDO, A. Sources of iron oxides in reddish brown soil profiles from calcarenites in southern Spain. Geoderma, 37:5766, 1986.

UNAMBA-OPARAH, I. The potassium status of the sandy soils of nothern I mo, state, Nigeria. Soil Sci., 139:437-445, 1985.

ZANGRANDE, M.B. Caracterização e interpretação para uso de um Podzólico Vermelho-Amarelo abrúptico dos platôs litorâneos no norte do E spírito Santo. Viçosa, Universidade Federal de Viçosa, 1985. 81p. (Tese de Mestrado) 
V.F. MELO et al.

R. Bras. Ci. Solo, 26:29-41, 2002 